\title{
Developing Leadership Capacity Through Organizational Learning
}

\author{
Julia Buchanan, National University
}

\begin{abstract}
The relationship of human development to leadership growth and organizational learning is becoming more significant as organizations recognize the value of skilled leadership. In order to foster collective intelligence and innovation in groups, leadership throughout an organization benefits from the understanding of processes involved in collectives or groups. The idea of creating a learning organization is gaining more attention as organizations strive to adapt and respond to a changing global environment in fast paced and demanding arenas. It is now becoming a needed skill to build a learning organization as a leadership competency. Those organizations that place learning as a priority will have an advantage over those that fail to learn and adapt. In order to understand how adult development is connected to organizational learning the work of Kegan (1982), Argyris (1992) and Senge (1990) will be examined. In addition the concept of dialogue, for learning, and creating culture will be explored in order to gain insight for developing leadership in organizational learning, Schein (2004); Isaacs (1996). Because of the growing complexity of the global environment, developing leadership in the organization is becoming more sophisticated in the ways in which learning is approached and orchestrated and therefore a greater understanding of leadership development is needed.
\end{abstract}

Keywords: Leadership Development, Learning Organization, Leadership Education

But when we speak from our true nature, the words we speak have a ring to them is unmistakable. This is the way the true becomes reintegrated into the beautiful and the good, for when we speak our voice, it has beauty, and speaks for more than ourselves, as if for everyone. (Isaacs, 1999, p.398)

\section{INTRODUCTION}

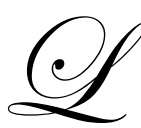
eadership is frequently involved with organizational learning and development. In order to explore indepth this relationship of leadership to learning and development in organizational life the work of Senge (1990) on creating the Learning Organization and Senge et al (2004) on Presence with Schein's (2004) work on Organizational Culture and Leadership will be reviewed. In order to further understand, organizational learning will be examined with concepts of human development and organizational culture. In addition the understanding of dialogue may hold significance for creating a learning organization and even a culture of learning. In many organizations there is a realization that the ability to adapt and constantly navigate change is essential to survival. Due to developments in technology and communications, commerce is quickly experiencing a change in the speed of business and therefore the pace of change has accelerated. The advent of world wide networks is creating communications and an emerging global arena never experienced to this level before. In order to create organizations that are equipped to survive or even excel in this global environment, there is a need for organizational learning and an understanding of adult development. As individuals acquire a greater understanding of the interaction of systems, a desire for a higher standard of organizational community may emerge. A metaphor for the new organization may be a well trained martial arts fighter. Generally in martial arts, the warrior is flexible, centered, improvisational and usually defensive; not seeking conflict but well able to survive it. Perhaps the organization equipped to react with flexibility, balance, and the ability to harness collective energy, will be able to react to unexpected threats or opportunities. 


\section{CREATING A LEARNING CULTURE}

As leadership develops the ability to make room to engage in a process of development, more members can share in the progression or evolution. Schein (2004) suggested that a leader poised to be effective in an unpredictable future will need to become more focused on the process of learning than on simply finding solutions to problems. Due to ever increasing complexity, those in leadership roles must rely on others in order to create solutions. Therefore the culture of the organization itself must become a learning culture (p.395). Learning to learn is a skill unto itself and can be embraced by members of the organization. The process of learning involves time, energy and resources. Reflection and experimentation must be valued in the culture of the learning organization. Senge (1990) suggested a similar idea, "The healthy corporations will be ones which can systemize ways to bring people together to develop the best possible mental models for facing any situation at hand" (p.112). In order to engage this process of learning including identifying mental models, embracing experimentation and risk, and the uncertainty with not knowing all the answers, leadership can value these in the culture (Schein, 2004).

The identification of mental models and the system in the mind impact the way adults approach learning and development. Argyris (1992) suggested that people connect learning to solving problems and correcting errors in the external environment. Ideal problem solving involves looking inward to reflect on one's behavior and identify ways that are inadvertently contributing to organizational problems. This reflection includes changing how one acts. Argyris also discussed the concept of double loop learning which involves more than considering concepts but also double or multiple levels of thinking. "Effective double loop learning is not simply a function of how people feel. It is a reflection of how they think - that is, the cognitive rules or reasoning they use to design and implement their actions" (Argyris, 1992, p.47). This type of awareness and learning allows individuals to access different levels of their thinking and feeling or experience.

In Senge's book, The Fifth Discipline he suggested that the Learning Organization is one which develops the capacity for organizational learning and therefore can adapt to situations that require innovation, learning and improvisation. According to Argyris, adults are highly skilled at protecting themselves from pain and threat posed by learning situations; consequently they fail to get the results they want. Argyris suggested that the ideal of organizational learning involves "organizational adaptability, flexibility...propensity to experiment...realization of human potential... and creation of settings as contexts for human development" $(1992, \mathrm{p} .1)$. These ideas integrate the potential for human development and the creation of the learning organization which is significant for leadership.

\section{LEARNING IMPROVISATION}

In my experience working with an organizational development cadre in Eugene, Oregon this type of learning (double loop) was a norm in the group. Due to trained and experienced members, including new trainees, the group could engage in conversation that went straight to the heart of issues with authentic communication and multiple levels of thought. Interestingly I found a similar description in the book Presence: "only about half the members knew one another in advance...but their shared experience building learning-oriented organizational cultures established a strong connection...the conversation was powerful...every person spoke straight from the heart" (Senge, Scharmer, Jaworski, and Flowers, 2004, p. 118). The freedom to be able to communicate genuinely and powerfully allowed complex problem solving and improvisation to flow through the cadre. The group effectively engaged the community in dialogue around difficult issues such as determining which schools to close. Because of the culture of learning and skilled dialogue, the community gave the group a standing ovation and the end of the difficult six week process. Perhaps because the community was involved in the process of a difficult decision it could stand by it and adapt to the loss rather than attack school officials. The process must have been sound if the public was moved to a standing ovation; they must have felt authentic engagement of the representatives in the process.

I recall a story from my research with this group, an incident involving large group consulting. As the facilitators came to an impasse in attempting to resolve an issue, they did not know where to go next in the discussion so they began to dialogue with one another in front of the group. One said to the other out loud "should we tell them we don't know what to do next?", the other responded "I'm not sure-do you think that they will 
question our competence if we do?" and so forth and the conversation evolved as the facilitators exposed their inner thoughts. This openness prompted the rest of the members to breakthrough with more candor thereby breakthrough to make significant progress on the issues. I have not forgotten this example not only because it was an interesting strategy, but because I recall the facilitator's facial expression and the look in his eyes when he told me the story. I sensed he was recalling the event as a time when he experienced a different type of learning. By engaging a different way of thinking and discovering he could invite the larger organization to join him in constructing or creating learning in the group. Even though the process involved vulnerability on his part, the learning was tremendous for the group.

\section{PRACTICES}

Creating new ideas and promoting innovation involves a skilled membership that knows how to learn as a continuous and collective endeavor, according to Senge (1990), "Generative learning, in my experience, requires managers with reflection and inquiry skills, not just consultants and planners" (p.115). The abilities that leadership needs in order to encourage learning have evolved into a greater need for understanding adult development and the learning process. Argyris suggested that multiple types of expertise are needed,

People at all levels of the organization must combine the mastery of some highly specialized technical expertise with the ability to work effectively in teams, form productive relationships with clients and customers, and critically reflect on and then change their own organizational practices. (1992, p.128)

Organizational learning involves processes that help individuals identify what mental models they are using. As more individuals become competent in identifying them organizational learning becomes more accessible. Slowing down to take time to engage in meaningful dialogue and reflection may also be significant in the organizational learning process. Senge stated that skills in reflection and awareness are also needed,

Skills of reflection concern slowing down our own thinking processes that we can become more aware of how we form our mental models and the ways they influence our actions. Inquiry skills concern how we operate in face to face interactions with others, especially in dealing with complex and conflictual issues. (1990, p.117)

Inquiry skills may also include understanding the organization as a whole system. Viewing the organization from within includes increasing the awareness of organizational culture. Senge et al, (2004) suggested utilizing Schein's understanding of organizational culture to see an organization from within. The authors suggest applying Schein's insights in a "disciplined way" to identify and interpret the culture of an organization. By paying attention to dynamics at meetings the culture of the organization is probably revealed more accurately than by reading corporate mission statements.

\section{DIALOGUE}

In order for leadership to support and build capacity for organizational learning, an understanding of dialogue and adult development is needed. Organizations benefit from leadership that understands how and when to incorporate dialogue. Dialogue is best used when team tensions exist; new projects are being undertaken, contentious situations involving open conflict and passion are involved or complex processes require agreement of how or where to begin (Isaccs, 1999). Dialogue allows for meaning to flow through. According to Isaacs (1999), dialogue requires a container, and a container can hold potential:

I will define leadership here as the capacity to hold the container for gradually larger sets of ideas, pressures, and people as the different crisis points unfold. Leadership itself, understood in this light, provides a container in which tremendous change can occur. (p. 255)

Isaacs suggested that that a container exists anytime there is a group of people. Isaacs stated "Dialogue is a process by which we can create containers that are capable of holding our experience in ever more rich and complex ways, making legitimate many approaches and styles" (1999, p.256). Leadership can also be a container for dialogue 
that releases potential, including organizational learning. The concept of dialogue when merged with Argyris (1992) ideas of a learning leader could have potential for implementing organizational learning. Argyris stated, "The learning leader must believe that humans can and will learn if they are provided the resources and the necessary psychological safety" (1992, p.396). The relationship of organizational learning to the processes of leadership through dialogue is helpful in understanding how to release collective intelligence and innovation throughout the organization.

Even though leadership can incorporate dialogue, it cannot over-utilize or be ignorant of the authority role. Dialogue is an evolving fluid motion and requires cooperation from those involved in the process:

Dialogue enables a 'free flow of meaning,' which has the potential of transforming the power relationships among the people concerned. As this free flow emerges, it becomes quite apparent that no one person owns this flow and that no one can legislate it. (Isaacs, 1999, p.395)

The process of dialogue can be powerful in organizational learning and adult development to promote learning. The process for dialogue includes guidelines to provide for effective discourse and psychological safety for participants. In addition dialogue can support collective leadership in the organization. Collective leadership involves a group of people attuned with one another to a degree that they operate in harmony with one another in the interests of the common enterprise (Dialogos Institute). Collective leadership is a model that benefits from organizational learning and the practice of dialogue to support the group becoming attuned.

\section{FOCUS ON EXPERIENTIAL PRACTICES}

According to Senge et al (2004) all learning integrates thinking and doing. Most of the time people are in reactive learning which can reinforce pre-established mental models. In order to learn differently a depth of awareness and an ability to see the larger wholes that generate "what is" and our connection to them, learning can dramatically change. These larger wholes, like all living systems keep features essential to their existence but also seek to evolve. The authors use the example of successful entrepreneurs they have interviewed that mentioned feeling they possessed an ability to recognize an emerging reality and act in harmony with it (p.11, 12). The ways that leadership development is promoted and cultivated is evolving in organizations to meet the need for a learning culture. The following table indicates capacities needed for effective leadership and suggested practices to promote a leadership culture and developing leaders in the organization:

\begin{tabular}{|l|l|}
\hline \multicolumn{1}{|c|}{ Leadership capacities } & \multicolumn{1}{c|}{ Suggested Practices to promote leadership culture } \\
\hline Challenge Status Quo & Systems thinking, analysis of system forces, surface assumptions \\
\hline Question norms & Interpret organizational culture, surface assumptions beneath norms \\
\hline Identify assumptions & Dialogue, promote questioning, look for mental models and theories in use \\
\hline $\begin{array}{l}\text { Frame adaptive work, define } \\
\text { realities }\end{array}$ & $\begin{array}{l}\text { Systems thinking and dialogue, interpret conflicts, look for data patterns, identify norms } \\
\text { linked to values }\end{array}$ \\
\hline Examine processes & $\begin{array}{l}\text { Debrief the process of doing the work, promote questioning of how and why the work was } \\
\text { done }\end{array}$ \\
\hline Create vision & Create meaning linked to the purpose of the work or organization \\
\hline Foster innovation & Promote dialogue and questioning, orchestrate conflict, use humor \\
\hline Develop others & Promote emotional intelligence, explicitly discuss personal growth as a reflective practice \\
\hline Inspire & $\begin{array}{l}\text { Create meaning through dialogue, create space to reflect on purpose and how it is connected } \\
\text { to the work }\end{array}$ \\
\hline Long term view & $\begin{array}{l}\text { Reflection on purpose, celebrate accomplishments of organization, consider impact of } \\
\text { globalization and technology to organization }\end{array}$ \\
\hline Originate & Create cohesive groups, honor creativity \\
\hline
\end{tabular}




\section{ADULT DEVELOPMENT}

In order to examine how adult development impacts organizational learning, a look into Kegan's (1982) theories of development may provide insight. Kegan suggested that humans develop over their lifetime through periods that are similar to stages or evolutionary truces between developments. Every evolutionary truce is somewhat of a solution to this tension between the yearnings for inclusion and differentiation (p.108). These evolutionary truces involve a culture of embeddedness that provides a holding environment during this process of development.The individual is affected by the environment they are immersed in or the culture of embeddedness. This culture of embeddedness provides a function of holding as the older previous self is let go of and the newer further developed self emerges. Kegan (1982) stated, "[Holding environments] are psychosocial environments that hold us with which we are fused and which let go of us" (p.116). The holding environments are connected to the culture of embeddedness and may impact the development of individuals in organizational settings. How leadership in organizations recognizes and understands the processes for human development may be connected to organizational learning as well. Kegan suggested the impact of the culture of embeddedness on the wider organization,

Each time a particular culture of embeddedness 'holds securely' it insures the integrity of the wider community of which each individual is a part; each time it assists in 'letting go' it attests to the community's greater loyalty to the person who develops than to the self the person has composed. (Kegan, 1982, pp.260-261)

The culture of embeddedness is significant in individual adult development and in the organization as a whole. This understanding becomes important as organizations respond to new and unanticipated challenges. They must consider which aspects of the learner's consciousness, behavior and competent action, as well as cultural and system-related issues of learning are being impacted in order to set priorities and enact practices (Kuper, 2006, p.2).

\section{THE UNCONSCIOUS IN LEARNING}

The concepts of Carl Jung on collective unconscious and sensing, thinking and feeling may provide additional understanding for the potential of organizational learning. Jung's ideas include the concept of the collective unconscious. The collective unconscious is universal like a large "pool" of reference and includes what he called archetypes. The archetypes are concepts that most humans connect with such as mythological symbols and common experiences. The archetypes include The Persona, the Anima-Animus, the Shadow and the Self. The "great mother" and the "trickster" are additional examples of archetypes. The Jungian archetypes may play a function in aiding individuals to find shared meaning, especially through a collective process such as dialogue.

Another of Jung's ideas was synchronicity which is defined as a coincidence that holds meaning with something other than probability involved. I find this concept fascinating and have experienced it frequently. In my own observations I seem to experience it more often when I am with people that are organized or excited around ideas or experiences. I recall one event in particular with an individual I worked with at summer camp. He was from Senegal and could not be more different from me in every way. We became friends following the work we did and would meet up from time to time. We experienced such frequent synchronicity that it would "freak out" members of our group of friends. We both took humor in these events and would just look at each other and laugh because we could not be more different from one another.

Jung also had ideas around how individuals process information which is a basis for the widely known Myers-Briggs Type Indicator test. The test or assessment determines 16 personality types which aid individuals in understanding themselves and how they process information, and also to help understand others (Daft, 2005.) The particular parts of the assessment that may most relate to organizational learning could be the sensing versus intuition and the thinking versus feeling. For example, perhaps individuals that are high in processing intuitively may especially embrace organizational learning through identifying patterns and experiencing "hunches." Another possibility is that those that are high in sensing attributes may excel utilizing all of their senses. Thinking versus feeling dimensions could bring entirely different processing to dialogue. The personality attributes based on Jung's theories provide multiple ways to experience and process organizational learning. 
An evolution in organizational learning may be possible as more and more individuals come to understand concepts such as dialogue, Jungian archetypes, collective unconscious and synchronicity. The practice and understanding of dialogue holds tremendous promise for the kind of learning that is not dependant on traditional topdown or dominator hierarchies. Individuals functioning at a sophisticated level or developed ability and awareness could help free organizations from depression and promote the release of individual and collective potential.

\section{INTEGRAL THEORY}

In order to explore an integrative understanding of organizational learning, using the All Levels, All Quadrants (AQAL) model found in Ken Wilber's (2000) work in a Theory of Everything is helpful. The AQAL model involves four quadrants including the upper left: Interior-Individual or "I", the upper right: ExteriorIndividual or "IT", the Lower left: Interior-Collective or "WE" and Lower Right, Exterior-Collective or ITS. Organizational learning involves all of the quadrants. The "I" quadrant involves the experience and processes of learning in the individual such as "my learning" and "my individual understanding." The upper right quadrant involves the "IT" or "the learning" that is acquired. The lower left quadrant involves the collective or "our understanding" and "our learning" as a group. The lower right quadrant involves the exterior collective or "organizational learning" as a social endeavor throughout organizations, for example the theories and thinking behind the learning organization or the development of organizational culture. The two left quadrants involve the interior and the two right quadrants address the exterior

To understand how the AQAL model helps with adult development and organizational learning is to gain perspective on the dimensions involved such as the interior and exterior processes of organizational learning. Because this paper is focused on organizational learning and adult development a look into the processes for the "WE" (lower left quadrant) and the "ITS" (lower right quadrant) may provide insight.

Organizational learning and development involves both the "WE" and the "ITS" as the vast majority of work in organizations is done in either small group or large groups and involves modern thinking about group dynamics or organizational systems. The work on dialogue by William Isaacs (1999) provides a means for learning and for engaging the phenomena of adult development. According to Isaacs, dialogue could serve as a vehicle for integrating of the "soft" and imprecise interior dimensions of human experience, like morals, artistic expression, meaning, and introspection with "harder" and objective exterior dimensions, like empirical research (p.386). Because learning involves all quadrants, dialogue can be an especially powerful approach for individual, collective and institutional learning. According to Kuper (2006), "To understand learning as a 'four quadrant affair' requires us to also embrace the left interior dimensions i.e. inner meaning" (p.2). Therefore the ability to participate in and facilitate dialogue as a means to organizational learning is an effective way to create capacity in individuals and groups. Argyris (1992) suggested that the understanding of complexity and systems will aid organizations in operating in a changing environment. Leadership cannot operate in a vacuum but rather must engage the collective intelligence and resources of the organization. Argyris stated,

As the world becomes more complex and interdependent, the ability to think systematically, to analyze fields of forces and understand their joint causal effects on each other, and to abandon simple linear causal logic in favor of more complex mental models will become more critical to learning. (p.401)

Due to the increasing complexity that organizations are experiencing, organizational learning theories have provided ways to approach change. Kuper stated, “...the inner lives of leaders and the collective spheres of learning need to be seen as co-determined by the behavioral and exterior dimensions" (2006, p.2).

\section{CONCLUSION}

Organizational learning is an activity which involves the individual experience as well as the collective. Creating a learning organization supports the needs of organizations that want to not only adapt to the emerging chaos and complexity of the global market but to release untapped potential of organizational members. The ideas of the collective unconscious may provide insight to exercising collective leadership. The practice of authentic and 
sophisticated dialogue will support organizational learning. In addition, the theories of adult development for the individual but also the role of the collective in creating the culture of embeddedness and a holding environment brings integrated understanding for leadership to do its job. An integral understanding of organizational learning helps leadership become more effective with the multiple levels of knowledge and skills necessary for reflection, dialogue, and creating the adaptable learning organization.

\section{REFERENCES}

1. Argyris, C. (1992). On organizational learning: Second edition. Oxford: Blackwell Business.

2. Dialogos International, LLC, (2003). Dialogos Intellectual Heritage. Retreived August 4, 2006. http://www.dialogos.com/aboutus/int her.html

3. Daft, R. L. (2005). The Leadership Experience. $3^{\text {rd }}$ edition, Toronto, Ontario: Thomson South Western.

4. Isaacs, W. (1999). Dialogue; and the art of thinking together. New York, NY: Random House.

5. Kazler, M. (2006) Jung's Conception of the Collective Unconscious, retrieved July 21, 2006. http://www.kheper.net/topics/Jung/collective unconscious.html

6. Kegan, R. (1982). The evolving self; Problem and process in human development. Cambridge, MA: Harvard University Press.

7. Kuper, W. (2006). Integrales Lernen in und von Organisationen (Integral Learning in and of Organizations), English summary, Integral Review. Retreived July 24, 2006. http://integralreview.org/current_issue/index.asp

8. Schein, E. (2004). Organizational culture and leadership. Third edition, San Francisco, CA: John Wiley and Sons, Inc.

9. $\quad$ Senge, P. (1990). The Fifth Discipline: The Art and Practice of the Learning Organization, New York, NY: Doubleday, pp.175-204.

10. Senge, P., Scharmer, C. O. Jaworski, J., \& Flowers, B. (2005). Presence; exploring profound change in people, organizations and society. Society for Organizational Learning, New York, N.Y: Doubleday.

11. Wilber, K. (2000) A theory of everything: an integral vision for business, politics science, and spirituality. Boston, MA: Shambala 
NOTES 